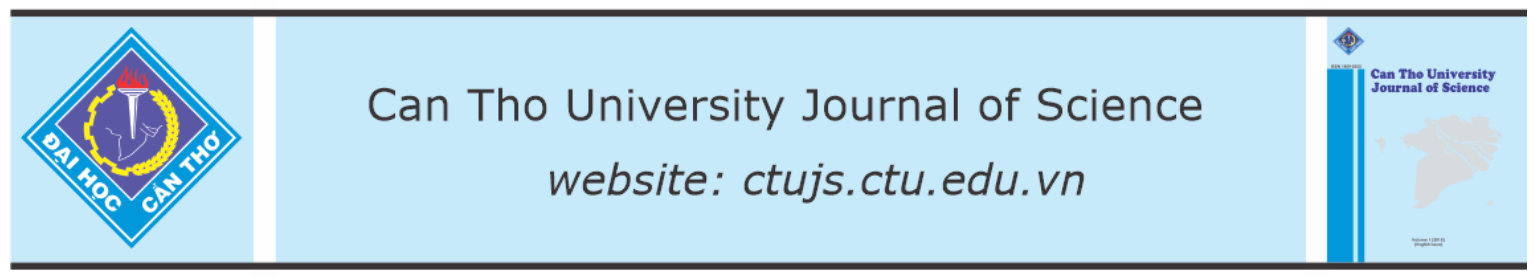

DOI: 10.22144/ctu.jen.2021.037

\title{
Effects of $\beta$-glucan and vitamin products supplementation into diets on growth performance of growing-finishing pigs in Ben Tre province
}

\author{
Tran Ngoc Bich ${ }^{1 *}$, Le Quang Trung ${ }^{1}$, Dang Thi Ngoc Truc ${ }^{1}$, Truong Van Hieu ${ }^{2}$, \\ Nguyen Thi Kim Quyen ${ }^{3}$ and Ngo Hoang Khanh ${ }^{4}$ \\ ${ }^{I}$ Department of Veterinary Medicine, College of Agriculture, Can Tho University, Viet Nam \\ ${ }^{2}$ Center for Climate Change Adaptation Research and Community Development Support, Tra Vinh \\ University, Viet Nam \\ ${ }^{3}$ Department of Husbandry and Veterinary studies, School of Agriculture and Aquaculture, Tra Vinh \\ University, Viet Nam \\ ${ }^{4}$ Center of High-tech Application in Agriculture, Ben Tre province, Viet Nam \\ *Correspondence: Tran Ngoc Bich (email: tnbich@ctu.edu.vn)
}

\section{Article info.}

Received 25 Feb 2021

Revised 29 Mar 2021

Accepted 15 Apr 2021

\section{Keywords}

Ben Tre province, $\beta$-glucan, growing-finishing pigs, vitamin, weight gain

\begin{abstract}
The aim of this study was to evaluate the influence of vitamin and $\beta$-glucan supplementations on growth performance of growing-finishing pigs in Ben Tre province. A total of 36 post-weaned piglets (Duroc $x$ YorkshireLandrace) with the initial live weight of $17.42 \mathrm{~kg} \pm 0.26$, was allotted into 3 treatments and 4 replications in a completely randomized design. There were three diets, including basal diet (BD) without any addition of $\beta$ glucan or vitamin (diet $C T$ ), the BD supplemented with vitamin (diet Vit) and the BD supplemented with $\beta$-glucan (diet Glu). The results on growth parameters indicated that final live weight $(\mathrm{kg})$, weight gain $(\mathrm{kg})$, and average daily gain (g/head/day) of pigs in the experimental diets were significantly higher $(P<0.01)$ than those in the control treatment. FCR was lowest in Glu and highest in the control $(P<0.01)$. Financial benefit based on feed and veterinary expenses was higher in the vitamin and $\beta$-glucan supplement diets than that of the control from $15.74 \%$ to $18.98 \%$, respectively.
\end{abstract}

\section{INTRODUCTION}

Pig is one of the most dominant livestock that is widely kept throughout the country of Viet Nam; however, almost all pig farms are small-holder in the whole country. Small-holder pig farming systems play an important role in food security and improving the livelihood of rural families, especially in the Mekong Delta. The farmers in this area have been more and more applying the new livestock husbandry model, advances in the progress of science and technology have been applied resulting in high livestock productivity and quality that contributes to the domestic market as well as exports (Le, 2010, 2015). Ben Tre province is one of the most developing pig production provinces in the Mekong Delta which a number of pigs accounted for 296,400 pigs compared with $1,685,900$ pigs of a total pig in the whole area (data of 2019) (General Statistics Office of Viet Nam, 2019). It has been realized that the diseases may lead to significant losses, besides the success. In the treatment or antibiotic supplementation in the diet of livestock, the use of antibiotics has brought positive 
results (Cromwell, 2002; Hahn et al., 2006; Park et al., 2018). However, long-term and nonspecific application of antibiotics may not only lead to the reduced function of the immune system but also result in bacterial resistance to antibiotics (Wang et al., 2008; $\mathrm{Vu}, 2012$ ). The search for alternatives to the feeding of antibiotics in animal nutrition is an ongoing problem under strict demand of the market when countries of the European Union banned the use of antibiotics in animal feed in 2006 (Amiri et al., 2011). Besides, there are many factors that place stress on pigs such as confinement, disease challenge and ambient temperature or their bioavailability/stability (Chae et al., 2000; Tian et al., 2001). Therefore, decreasing the pig's stress through the external factors while increasing the growth performance and nutrient digestibility is the necessary requirement, especially under climate change, nowadays. The idea of creating immunomodulator products added to feed to improve growth performance, health status and enhance the productivity of livestock has been increasingly interested recently. Several methods have been studied, they are effective to replace antibiotics or reduce stress through the environment for livestock such as $\beta$-glucan as well as vitamins (Wang et al., 2008; Le et al., 2016). Vitamin plays an important role in the maximal performance of weaning pigs, increasing daily gain, reducing feed cost and nutrient excretion with economic and environmental benefits (Chae et al., 2000; Le et al., 2016). Using $\beta$-glucan in animal feed revealed the antioxidative, antiviral and immunomodulatory (Hahn et al., 2006; Wang et al., 2008). From the actual requirement of production, the study aims to evaluate the effects of $\beta$-glucan and vitamin products used as a feed supplement for growingfinishing pigs about growth performance, feed efficiency, and economic benefit obtained in the practical livestock condition of Ben Tre province.

\section{MATERIALS AND METHODS}

\subsection{Materials}

\subsubsection{Experimental time and location}

This study was carried out at the farm of the Center of High-tech Application in Agriculture, Chau Thanh district, Ben Tre province, Viet Nam. The province has a climate of tropical monsoon setting with the average diurnal temperature range is 26$27^{\circ} \mathrm{C}$. Two seasons characterize the study area; a rainy season is from May to October, and a dry season is from November to April with no clear-cut demarcation. Annual rainfall ranges from 1,250 to
1,500 mm (https://www.bentre.gov.vn). The entire study lasted for 4 months spanning from June to October 2020.

\subsubsection{Experimental animals}

A total of 36 piglets [Duroc $\mathrm{x}$ (Yorkshire $\mathrm{x}$ Landrace)] in the post-weaned period was chosen for this study. The average initial live weight of weaned pigs was about $17.42 \mathrm{~kg} \pm 0.26$. Piglets were reared in a clean experimental house with slatted floor pens. Each pen contained a self-feeder and a nipple drinker to allow pigs access to feed and water. A week before the arrival of the animals, the pens were cleaned and subsequently disinfected to reduce the risk of disease infection. On arrival at the experimental pens, the pigs were provided with a two-week period of equilibration to acclimatize to the environment, feed and water.

\subsubsection{Experimental feed}

The basal feed for experimental pigs was the compound feed (Guyomarc'h, Viet Nam). The chemical composition and metabolizable energy of basal feed were presented in Table 1 .

Table 1: Energy and chemical composition of the basal diet for growing-finishing pigs

\begin{tabular}{|c|c|c|}
\hline Items & $\begin{array}{r}\text { Growing } \\
\text { phase }^{(*)}\end{array}$ & $\begin{array}{r}\text { Finishing } \\
\text { phase }^{(*)}\end{array}$ \\
\hline $\mathrm{DM}(\%)$ & 13 & 13 \\
\hline $\mathrm{cal} / \mathrm{kg}$ ) & 3,000 & 3,000 \\
\hline CP (\%) & 16.0 & 14.5 \\
\hline $\mathrm{CF}(c$ & 7.0 & 7.0 \\
\hline Lysine & 0.90 & 0.78 \\
\hline+ Cystine $(\%)$ & 0.55 & 0.55 \\
\hline Calcium (min - max) $(\%)$ & $0.6-1.2$ & $0.6-1.2$ \\
\hline $\begin{array}{l}\text { Phosphorus total (min - } \\
\max (\%)\end{array}$ & $0.5-0.9$ & $0.5-0.9$ \\
\hline
\end{tabular}

* Common growing and finishing diets were fed from approximately 15 to $60 \mathrm{~kg}$, 60 to until market, respectively

Additional products of experimental diets included $\beta$-glucan (Bio - Pharmachemie Co.) and vitamin products (Hero Veterinary Co.) as follows:

$\beta$-glucan product: $1,3-1,6-\beta$-glucan (1\%), antibiotic (none)

Vitamin product: Vitamin A $(900,000$ UI), vitamin D3 (1,000,000 UI), vitamin E (2,000 mg), vitamin B1 (300 mg), vitamin B2 (200 mg), vitamin B3 (1,000 mg), vitamin B6 (300 mg), vitamin B9 (500 $\mathrm{mg})$ and vitamin $\mathrm{C}(2,000 \mathrm{mg})$. 


\subsection{Methods}

\subsubsection{Experimental design}

The experiment was arranged in a completely randomized design with 3 treatments and 4 replicates ( 3 pigs per pen). Treatments were:

Control (CT): Basal diet (BD) without any supplementation

Vit: $\mathrm{BD}$, added vitamin at a dose of $4.0 \mathrm{~g} / \mathrm{kg}$ feed

Glu: BD, added $\beta$-glucan at a dose of $2.0 \mathrm{~g} / \mathrm{kg}$ feed

\subsubsection{Measurements}

Performances of pigs was the live weight $(\mathrm{kg} / \mathrm{head})$, weight gain (kg/head) and average daily gain (g/head/day) (ADG); average daily feed intake (g/head/day) (ADFI); feed intake (FI), feed conversion ratio (FCR); the cost of feed $/ \mathrm{kg}$ weight gain of pigs and financial benefit (feed + veterinary): the total cost of feed and veterinary medicine compared to the total weight gain of pigs during the experimental stage (Dang, 2005; Nguyen, 2008).

\subsection{Statistical analysis}

The data were analyzed by ANOVA using the General Linear Model of Minitab Statistical Software version 16.0 (Ryan et al., 2012). The Tukey test was used for paired comparisons of means at 5\% significant level.

\section{RESULTS AND DISCUSSION}

\subsection{Growth performance of growing-finishing pigs}

\subsubsection{Live weight}

The live weight of the experimental pigs was presented in Table 2.

Table 2. Live weight (kg/head) of growingfinishing pigs in different period

\begin{tabular}{|c|c|c|c|c|c|}
\hline Items & $\mathrm{CT}$ & Vit & Glu & SEM & $\mathbf{P}$ \\
\hline $\begin{array}{l}\text { Initial } \\
\text { weight }\end{array}$ & 17.83 & 17.54 & 16.88 & 0.44 & 0.30 \\
\hline $\begin{array}{l}\mathrm{M} \\
\mathrm{w}\end{array}$ & $56.00^{\mathrm{b}}$ & $61.17^{\mathrm{a}}$ & $60.04^{\mathrm{a}}$ & 1.50 & 0.05 \\
\hline $\begin{array}{l}\text { Final } \\
\text { weight }\end{array}$ & $100.92^{b}$ & $111.08^{\mathrm{a}}$ & $112.33^{\mathrm{a}}$ & 2.29 & 0.01 \\
\hline
\end{tabular}

$a, b:$ Means with different letters in the same row are significantly different $(P<0.05)$
Table 2 showed that there was no significant difference $(\mathrm{P}>0.05)$ in the initial live weight of piglets; this proved that piglets were relatively selected for equal weight in the experiment. The priority at the beginning of the experiment was to create homogeneous groups as far as weight was concerned. Therefore, the average initial weight was $17.42 \mathrm{~kg}$ that was an auspicious beginning to evaluating the increase of pigs after the experiment. After 8 weeks of feeding, the body-weight of pigs was different $(\mathrm{P}<0.05)$ between the Vit, Glu and control groups. The average weight in this group was $60.61 \mathrm{~kg}$ compared with the $56.00 \mathrm{~kg}$ average weight of the control group. As far as the live weight of pigs was concerned, it was higher in the midterm weight for Vit and Glu groups compared with the control group, but not significantly different between Vit and Glu groups $(\mathrm{P}>0.05)$. In the final weight, the live weight was higher compared with the midterm weight as well as between the Vit, Glu and control groups; however, there was no significant difference between Vit and Glu groups $(P>0.05)$. Chae et al. (2000) reported that additional vitamins helped to reduce the stress on pigs through the outside environment, contribute to the digestion in pig's gut as well as improve the feed intake, thus they can enhance pig's growth. This might be explained that more vitamin in the diet helped pigs grow better because of improved digestion (vitamin $\mathrm{C}$ can reduce stress on pigs while water soluble vitamins might increase nutrient absorption) (Chae et al., 2000; Eicher et al., 2006). Similar results were verified by Le et al. (2016), who observed that additional feeding of vitamins improved the live weight of pigs compared to control $(\mathrm{P}<0.05)$ on the last day (56 days). Besides, glucans originally used as broad-spectrum immune and it can also improve gastrointestinal health by increasing mucosal barrier functions and contributing to the increase of animal growth (Vetvicka et al., 2014). The research results of Nguyen et al. (2014) showed that supplementation of $\beta$-glucan into the diet increased the pig's appetite. Therefore, the pigs' ability to digest and absorb was higher than the control group. Similarly, the study of Nguyen and Huynh (2016) also found that the weight gain of pigs in the $\beta$ glucan treatment was higher than the control treatment, the difference was statistically significant $(\mathrm{P}<0.05)$.

\subsubsection{Weight gain}

Weight gain of pigs fed in different treatments at different point times was presented in Table 3 . 
Table 3. Weight gain $(\mathrm{kg} / \mathrm{head})$ of growingfinishing pigs in the experiment

\begin{tabular}{lrrrrr}
\hline Items & CT & Vit & Glu & SEM & P \\
\hline $0-60$ days & $38.17^{\mathrm{b}}$ & $43.63^{\mathrm{a}}$ & $43.17^{\mathrm{a}}$ & 1.43 & 0.02 \\
\hline $\begin{array}{l}\text { 60-120 } \\
\text { days }\end{array}$ & $44.92^{\mathrm{b}}$ & $49.92^{\mathrm{a}}$ & $52.29^{\mathrm{a}}$ & 1.23 & 0.01 \\
\hline $0-120$ days & $83.08^{\mathrm{b}}$ & $93.54^{\mathrm{a}}$ & $95.46^{\mathrm{a}}$ & 2.24 & 0.01 \\
\hline
\end{tabular}

${ }^{a, b}:$ Means with different letters in the same row are significantly different $(P<0.05)$

As shown in Table 3, the weight gain $(\mathrm{kg} / \mathrm{head})$ of pigs from the post-weaning stage to 60 days at different groups was a significant difference $(\mathrm{P}<0.05)$ among the treatments. Pigs in Glu and Vit groups grow better than others; however, there was no significant difference between Vit and Glu groups $(\mathrm{P}>0.05)$. The weight gains of pigs during the period from 60 to 120 days were significantly different $(\mathrm{P}<0.01)$ between the Vit, Glu and the control groups. This result showed that in this period the pigs responded well to vitamin and $\beta$-glucan products, leading to higher growth. However, there was no significant difference between additional vitamins and $\beta$-glucan into the diet of experimental pigs $(\mathrm{P}>0.05)$. Vitamins $\mathrm{A}, \mathrm{E}, \mathrm{C}$ and $\mathrm{B}$-vitamins may increase pig's appetite, thereby providing better nutrition for the pig body (Chae et al., 2000; Duong, 2008); vitamin C positively affects the reduction of environmental impacts such as temperature and humidity, thereby helping to reduce natural stresses in pigs, helping pigs with less disease and high weight gain (Eicher et al., 2006; Duong, 2008). This result was consistent with Stahly et al. (1995, 1997), who demonstrated that additional feeding of B-vitamins or vitamin $\mathrm{A}, \mathrm{E}$ and $\mathrm{C}$ higher than the National Research Council (NRC) (1988) requirement improved the weight gain of growing pigs. Chae et al. (2000) also agreed that the increment of weight gain by supplementation of $150-250 \%$ vitamin listed in NRC (1998) requirement in finishing pigs. Similarly, Le et al. (2016) suggested that vitamin product supplementation into the diet might improve the weight gain of growing pigs. On the other hand, Wang et al. (2008) reported that $\beta-1,3 / 1,6$-glucan might contribute as a transient immune-enhancing effect on the cellular and humoral immune function and growth performance of weaning piglets. Moreover, Nguyen et al. (2014) and Nguyen and Huynh (2016) shared similar results of the addition of $\beta$-glucan in pig's diet to make more optimal weight gain of pigs. The addition of $\beta$-glucan into the diet helped to improve the growth rate and tended to increase the feed intake as well as feed efficiency of pigs during the experimental period (Hahn et al., 2006; Park et al., 2018).

\subsubsection{Average daily gain ( $A D G)$}

Results on ADG of weaning pigs in different periods was presented in Table 4.

Table 4. Average daily gain (g/head/day) of experimental pigs in different periods

\begin{tabular}{lrrrrr}
\hline \multicolumn{1}{c}{ Items } & CT & Vit & \multicolumn{2}{c}{ Glu SEM } & P \\
\hline $\begin{array}{l}0-60 \\
\text { days }\end{array}$ & $636.10^{\mathrm{b}}$ & $719.40^{\mathrm{a}}$ & $727.10^{\mathrm{a}}$ & 2.38 & 0.02 \\
\hline $\begin{array}{l}60-120 \\
\text { days }\end{array}$ & $748.60^{\mathrm{b}}$ & $831.90^{\mathrm{a}}$ & $871.50^{\mathrm{a}}$ & 2.53 & 0.01 \\
\hline $\begin{array}{l}0-120 \\
\text { days }\end{array}$ & $692.40^{\mathrm{b}}$ & $779.50^{\mathrm{a}}$ & $795.50^{\mathrm{a}}$ & 1.86 & 0.01 \\
\hline
\end{tabular}

${ }^{a, b}$ : Means with different letters in the same row are significantly different $(P<0.05)$

The results in Table 4 indicated that ADG $(\mathrm{g} / \mathrm{h}$ ead/day) of pigs from post-weaning stage to 120 days at different groups was a significant difference $(\mathrm{P}<0.01)$ among the treatments. However, there was no difference between Vit and Glu groups $(\mathrm{P}>0.05)$. Additional feeding of vitamin and $\beta$-glucan products during 0-60 days were different $(\mathrm{P}<0.05)$ among the ADG of experimental pigs. During the period from 60-120 days, pigs in Vit and Glu groups were more adaptable with the additional diet compared with control groups, there was a significant difference $(\mathrm{P}<0.01)$. Park et al. (2018) reported that pigs fed diets containing $0.4 \% \beta$-glucan was higher ADG compared to the control diet. In another study, $\mathrm{Li}$ et al. (2006) discussed the effects of $\beta$-glucan which was extracted from Saccharomyces cerevisiae on growth performance and the immunological of pigs. The findings of the study suggested that $\beta$-glucan inclusion in the diet might improve both the growth and immune in weaned pigs. Furthermore, Hahn et al. (2006) also found a linear increase in ADG and nutrient digestibility of pigs into the treatment which added $0.01-0.04 \% \beta$-glucan. This result was similar to the research result of Nguyen et al. (2014); Nguyen and Huynh (2016), the addition of $\beta$-glucan into the diet of experimental pigs might improve ADG (g/head/day) of pigs compared to the control treatment $(\mathrm{P}<0.05)$. Moreover, this result showed that the diet with vitamin products $(\mathrm{A}, \mathrm{D}, \mathrm{E}, \mathrm{C}, \mathrm{B}$ vitamins) was a good effect on the weight gain of experimental pigs. The addition of vitamin levels to pig diets helped optimize weight gain (Chae et al., 2000). The result was also consistent with the study of Lohakare et al. (2006), Le et al. (2016), who 
observed that ADG of pigs in treatments supplemented with vitamin premixes (A, D, E and B-vitamins) was higher compared to pigs in the control treatment. This proved that the pigs have had a change in the digestive system, adapted to the mixed feed, so there was a difference in absolute weight gain between Vit, Glu and C groups.

\subsubsection{Feed intake (FI) and feed conversion ratio (FCR)}

Results on feed intake, feed conversion ratio of weaning pigs were presented in Table 5.

Table 5. Feed intake, feed conversion ratio of growing-finishing pigs

\begin{tabular}{lrrrrr}
\hline Items & CT & Vit & Glu & SEM & P \\
\hline ADFI (kg/head/day) & 1.79 & 1.88 & 1.90 & 0.06 & 0.40 \\
FI (kg/pen/period) & 861.30 & 903.30 & 910.30 & 6.83 & 0.44 \\
Weight gain (kg/pen/period) & $332.33^{\mathrm{b}}$ & $374.17^{\mathrm{a}}$ & $381.83^{\mathrm{a}}$ & 2.24 & 0.02 \\
FCR & $2.59^{\mathrm{a}}$ & $2.41^{\mathrm{b}}$ & $2.38^{\mathrm{b}}$ & 2.41 & 0.01 \\
\hline
\end{tabular}

${ }^{a, b}$ : Means with different letters in the same row are significantly different $(P<0.05)$

ADFI: Average daily feed intake ( $\mathrm{kg} / \mathrm{head} / \mathrm{day})$

There was no difference $(\mathrm{P}>0.05)$ in FI $(\mathrm{kg} / \mathrm{pen})$ among dietary groups, this was partially in agreement with NRC (1998). ADFI (kg/head/day) was no significant difference in the initial weight of pigs among all experiments $(\mathrm{P}>0.05)$. But there was a statistically significant difference $(\mathrm{P}<0.01)$ in weight gain $(\mathrm{kg} / \mathrm{pen})$ between dietary groups and the control group, during the period. The study of Park et al. (2018) also showed that dietary supplementation of $\beta$-glucan linearly increased apparent total tract digestibility of dry matter and energy during 1-14 and 1-42 days as dietary $\beta$ glucan increased from 0.1 to $0.4 \%$; however, there was no difference $(\mathrm{P}>0.05)$. Similar results were verified by Hahn et al. (2006) and Wang et al. (2008), no effect ( $P>0.05)$ was found on ADFI of experimental pigs that added $\beta$-glucan into the diet compared with the control group. However, FCR of experimental pigs was improved between the groups that used vitamin and $\beta$-glucan products as compared to that in the control group $(\mathrm{P}<0.01)$. When the $\beta$-glucan product was supplied to the diet, the functional feed efficiency in pigs had been promoted, helping pigs grow better. Even though Wang et al. (2008) and Park et al. (2018), who observed that additional feeding of $\beta$-glucan requirement improved the production of digestive and absorptive capacities of the small intestine in the brush fringing intestinal epithelium while vitamin premixes (A, D, E, C and B-vitamins) might reduce the effect of environmental impacts such as temperature and humidity, thereby helping to reduce natural stresses in pigs, helping pigs with less disease and high weight gain (Eicher et al., 2006; Duong, 2008; Le et al., 2016).

\subsection{Financial benefit}

Results on the financial benefit were presented in Table 6.

Table 6. Financial benefits based on feed

\begin{tabular}{lrrr}
\hline Items & CT & Vit & Glu \\
\hline Total of weight gain (kg/pen) W & 332.33 & 374.17 & 381.83 \\
Feed consumption (kg/pen) & 861.3 & 903.3 & 910.3 \\
Cost of feed (kg/pen) (thousand VND) A & 9,382 & 9,840 & 9,916 \\
Cost of products (thousand VND/pen) B & 0 & 290 & 310 \\
Cost (feed + products)/kg weight gain [(A + B)/W] (thousand VND) & 28.23 & 27.07 & 26.78 \\
Comparison (\%) & 100 & 95.90 & 94.86 \\
\hline
\end{tabular}

Basal feed: 10,893 (VND/kg); vitamin: 80,000 (VND/kg); $\beta$-glucan: 85,000 (VND/kg)

Table 6 showed that the cost of feed per pen added vitamin and $\beta$-glucan were higher than control. Feed costs of products for experimental pigs that supplied $\beta$-glucan were slightly higher. However, the cost of feed per $\mathrm{kg}$ of weight gain of these treatments was lower compared with control. The feed cost $/ \mathrm{kg}$ of weight gain of pigs in the control treatment was $100 \%$, the level of costs in the vitamin and $\beta$-glucan treatments lower from 4.10 and $5.14 \%$. The best effect on the feed cost was treatment Glu, followed by Vit. 


\subsection{Financial benefit based on feed of the experiment}

Results on the financial benefit based on feed and veterinary medicine of the experiment were presented in Table 7.

Table 7 indicated that the cost of feed was not significantly different in the whole experiment. Feed costs for experimental pigs that supplied $\beta$ glucan were slightly higher; however, the veterinary cost was less significant than the control group.
Thereby, it led to total cost of feed and veterinary medicine was lower significance compared to the control group. Regarding expenses (feed + veterinary) of the whole experiment in control was higher than other treatments (although the cost has been calculated). The best effect on the feed cost was treatment Glu, followed by Vit (higher than $18.98 \%$ and $15.74 \%$ compared to control, respectively).

Table 7. Financial benefit based on feed and veterinary medicine of the experimental treatments

\begin{tabular}{lrrr}
\hline Items & CT & Vit & Glu \\
\hline Total of weight gain (kg/treatment) & 997.00 & $1,122.50$ & $1,145.50$ \\
Total income (thousand VND) (D) & 71,784 & 80,820 & 82,476 \\
Feed consumption (kg) & 2,584 & 2,710 & 2,731 \\
Cost of feed (thousand VND) (A) & 28,148 & 29,520 & 29,749 \\
Cost of products (thousand VND) (B) & 0 & 870 & 930 \\
Cost of veterinary medicines (VND) (C) & 257 & 224 & 185 \\
The total cost/treatment (thousand VND) & 28,405 & 30,614 & 30,864 \\
Income (-) expenses (thousand VND) & 43,379 & 50,206 & 51,612 \\
Comparison (\%) & 100 & 115.74 & 118.98 \\
\hline
\end{tabular}

Basal feed: 10,893 (VND/kg); vitamin: 80,000 (VND/kg); $\beta$-glucan: 85,000 (VND/kg); pig price: 72,000 (VND/kg)

\section{CONCLUSION AND SUGGESTION}

Based on these results from the present study, performance of pigs using $\beta$-glucan supplement in diets was higher than that in control. Feed efficiency of pigs in the $\beta$-glucan supplement diets was also improved. Financial benefit (feed + veterinary) in the treatment of additional $\beta$-glucan was the highest up to $18.98 \%$.

\section{REFERENCES}

Amiri, M., Hashemi, M., \& Ahmadi, F. (2011). Effects of feed type with/without nanosil on cumulative performance, relative organ weight and some blood parameters on broilers. Global Veterinaria, 7(6), 605609.

Chae, B. J., Choi, S. C., Cho, W. T., Han, I. K., \& Sohn, K. S. (2000). Effects of inclusion levels of dietary vitamin and trace mineral on growth performance and nutrient digestibility in growing pigs. AsianAustralasian Journal of Animal Sciences, 13(10), 1440-1444. https://doi.org/10.5713/ajas.2000.1440

Chen, Y. J., Min, B. J., Cho, J. H., Kwon, O. S., Son, K. S., Kim, H. J., \& Kim, I. H. (2006). Effects of dietary Bacillus-based probiotic on growth performance, nutrients digestibility, blood characteristics and fecal noxious gas content in finishing pigs. Asian-Australasian Journal of Animal

\section{ACKNOWLEDGMENT}

The study was financially supported by the Ben Tre Department of Science and Technology. The authors are indebted to the Center of High-Tech Application in Agriculture in Ben Tre province for their help in carrying out this experiment.

Sciences, 19(4), 587-592.

https://doi.org/10.5713/ajas.2006.587

Cromwell, G. L. (2002). Why and how antibiotics are used in swine production. Animal Biotechnology, 13(1), 7-27. https://doi.org/10.1081/ABIO120005767

Dang, V. B. (2005). Breeding stock. School of Education University Publisher, Ha Noi.

Duong, T. L. (2008). Feed and poultry nutrition. Agricultural Publisher, Ho Chi Minh City.

Eicher, S. D., McKee, C. A., Carroll, J. A., \& Pajor, E. A. (2006). Supplemental vitamin $C$ and yeast cell wall $\beta$ glucan as growth enhancers in newborn pigs and as immunomodulators after an endotoxin challenge after weaning. Journal of Animal Science, 84(9), 23522360. https://doi.org/10.2527/jas.2005-770

General Statistics Office of Viet Nam. (2019). The number of pigs at the point of 1/10 of each year by locality. www.gso.gov.vn. 
Hahn, T. W., Lohakare, J., Lee, S. L., Moon, W. K., \& Chae, B. J. (2006). Effects of supplementation of $\beta$ glucans on growth performance, nutrient digestibility, and immunity in weanling pigs. Journal of Animal Science, 84(6), 1422-1428. https://doi.org/10.2527/2006.8461422x

Le, T. M. (2010). Techniques for raising pigs. Agricultural Publisher, Ho Chi Minh City.

Le, T. M. (2015). The effects of probiotic supplementation on growth performance of weaning pigs in the Mekong Delta of Vietnam. Can Tho University Journal of Science, 1, 33-38. https://doi.org/10.22144/ctu.jen.2015.022

Le, T. M., Le, Q. T., Huynh, M. T., Vo, V. S. \& Nguyen, D. H. (2016). Effects of ADE-B-vitamin and Bvitamin-C on growth performance in growing pigs. Journal of Animal Science and Technology, 210, 12-18.

Li, J., Li, D. F., Xing, J. J., Cheng, Z. B. \& Lai, C. H. (2006). Effects of $\beta$-glucan extracted from Saccharomyces cerevisiae on growth performance and immunological and somatotropic responses of pigs challenged with Escherichia coli lipopolysaccharide. Journal of Animal Science, 84(9), 2374-2381. https://doi.org/10.2527/jas.2004-541

Lohakare, J., Lee, S. K., \& Chae, B. J. (2006). Effect of dietary fat-soluble vitamin on growth performance and nutrient digestibility in growing pigs. AsianAustralasian Journal of Animal Sciences, 19(4), 563567. https://doi.org/10.5713/ajas.2006.563

Modesto, M., D'Aimmo, M. R., Stefanini, I., Trevisi, P., De Filippi, S., Casini, L., ... \& Biavati, B. (2009). A novel strategy to select Bifidobacterium strains and prebiotics as natural growth promoters in newly weaned pigs. Livestock Science, 122(2-3), 248-258. https://doi.org/10.1016/j.livsci.2008.08.017

Nguyen, M. T., Mai, V. T. D., \& Do, V. A. K. (2014). Influence of $\beta$-glucans and vitamin $\mathrm{C}$ supplementation on growth performance in weanling pigs. Can Tho University Journal of Science, Special issue: Agriculture, 89-95.

Nguyen, T. T., \& Huynh, T. T. (2016). Effects of supplementation of Beta-glucan and Tra catfish (Pangasius hypophthalmus) by-product protein hydrolysate on the performance of weaned piglets. Can Tho University Journal of Science, 43, 74-81. https://doi.org/10.22144/ctu.jvn.2016.077
Nguyen, T. (2008). The higher of pig breeding and techniques for raising pigs. Agricultural Publisher, Ha Noi.

NRC. (1988). Nutrient requirement of swine ( $\left.9^{\text {th }} \mathrm{ed}.\right)$. National Academy Press Publisher.

NRC. (1998). Nutrient requirement of swine (10 $\left.{ }^{\text {th }} \mathrm{ed}.\right)$. National Academy Press Publisher.

Park, J. H., Lee, S. I., \& Kim, I. H. (2018). Effect of dietary $\beta$-glucan supplementation on growth performance, nutrient digestibility, and characteristics of feces in weaned pigs. Journal of Applied Animal Research, 46(1), 1193-1197. https://doi.org/10.1080/09712119.2018.1481855

Ryan, B., Joiner, B. L., \& Cryer, J. D. (2012). Minitab statistical software release 16. Cengage Learning Publisher.

Stahly, T. S., Williams, N. H., Swenson, S. G., \& Ewan, R. C. (1995). Dietary B vitamin needs of high and moderate lean growth pigs fed from 9 to $28 \mathrm{~kg}$ body weight. Journal of Animal Science, 73(1), 193-198.

Stahly, T. S., Cook, D. R., \& Ewan, R. C. (1997). Dietary vitamin A, E, C needs of pigs experiencing a low or high level of antigen exposure. Journal of Animal Science, 75(1), 194-202.

Tian, J. Z., Lee, J. B., Kim, J. D., Han, Y. K., Park, K. M., \& Han, I. K. (2001). Effects of different levels of vitamin-mineral premixes on growth performance, nutrient digestibility, carcass characteristics and meat quality of growing-finishing pigs. AsianAustralasian Journal of Animal Sciences, 14(4), 515524. https://doi.org/10.5713/ajas.2001.515

Vetvicka, V., Vannucci, L., \& Sima, P. (2014). The effects of $\beta$-Glucan on pig growth and immunity. The Open Biochemistry Journal, 8, 89-93. https://doi.org/10.2174/1874091X01408010089

Vu, D. G. (2012). Probiotic in pig husbandry: Mechanism of action and usage. Animal husbandry informations. Vietnam New Agency Publishing House, 65, 56-60.

Wang, Z., Guo, Y., Yuan, J. \& Zhang, B. (2008). Effect of dietary $\beta$-1,3/1,6-glucan supplementation on growth performance, immune response and plasma prostaglandin E2, growth hormone and ghrelin in weanling piglets. Asian-Australasian Journal of Animal Sciences, 21(5), 707-714. https://doi.org/10.5713/ajas.2008.70559 